\title{
A AVALIAÇÃO DO PROCESSO DIDÁTICO-PEDAGÓGICO NA EDUCAÇÃO A DISTÂNCIA: UM ESTUDO DE CASO
}

\author{
Elisa Netto Zanette ${ }^{1}$ \\ Nara Cristine Thomé Palácios Cechella ${ }^{2}$ \\ Michele Domingos Schneider ${ }^{3}$
}

\section{INTRODUÇÃO}

O acesso à Educação Superior na sociedade do conhecimento, como cita Lévy (1999, p. 160), tornou-se essencial para a atuação dos sujeitos no mercado de trabalho, que exige competências diferenciadas dos profissionais. A capilaridade das redes e o desenvolvimento continuado de Tecnologias da Informação e Comunicação (TICs) promoveram o acesso a elas nas mais diversas instâncias de atuação do homem. Provocaram mudanças substanciais nas relações humanas, onde as redes potencializaram novas formas de se relacionar nas diferentes dimensões: social, econômica, política e cultural.

As demandas de formação de profissionais, com perfil de atuação na sociedade da informação, são os desafios impostos às Instituições de Ensino Superior (IES). Com isso, ampliaram-se as opções formativas diferenciadas no contexto dos atuais e novos cursos superiores. A Educação a Distância (EaD) apresenta-se como opção na formação de sujeitos que necessitam de maior flexibilidade de tempo e espaço, respeitando suas limitações e possibilidades de acesso.

A diversidade de oferta de modelos híbridos de ensino (semipresencial e a distância) nas IES, ressignificados na contemporaneidade, promoveram o surgimento de centros, setores ou núcleos de EAD, como afirma ZANETTE et. al. (2012). Na Universidade do Extremo Sul Catarinense (UNESC), esse processo iniciou em 2001, com ações pontuais em cursos de extensão e aperfeiçoamento, em parceria com outras instituições. Em 2013, foi ofertado o primeiro curso de graduação nessa modalidade -

\footnotetext{
${ }^{1}$ UNESC, enz@unesc.net

2 UNESC, nara@unesc.net

${ }^{3}$ UNESC, michele.schneider@unesc.net
} 
Tecnologia em Gestão Comercial (TGC). No presente estudo, apresentam-se os resultados da pesquisa cujo objetivo foi avaliar o processo didático-pedagógico do referido curso. A avaliação ocorreu a partir análise documental do curso e dos relatórios gerados pelo Setor de Avaliação Institucional (SEAl) na percepção dos acadêmicos sobre o processo educativo. A relevância do processo de avaliação, segundo Cortelazzo (2013), situa-se no objetivo de redirecionar as ações, orientações e replanejamento das atividades. Constitui-se como um dos fundamentos da EaD e contempla aspectos relevantes para a melhoria dos projetos.

\section{A METODOLOGIA DA PESQUISA}

De acordo com Oliveira (1999, p. 15), "a pesquisa tem por objetivo estabelecer uma série de compreensões no sentido de descobrir respostas para as indagações ou questões que existem em todos os ramos do conhecimento". No presente estudo, objetivou-se avaliar o processo didático-pedagógico do primeiro curso superior na modalidade de EaD. A pesquisa foi desenvolvida no período de 2014 a 2015. É bibliográfica e contempla as abordagens quali-quantitativas de coleta e análise de dados. Para Sampieri et.al. (2006, p. 15), "a pesquisa qualitativa dá profundidade aos dados, a dispersão, a riqueza interpretativa, a contextualização do ambiente, os detalhes e as experiências únicas".

A população-alvo da pesquisa foi composta pelos acadêmicos da turma 1 ( $4^{\text {a }}$ fase) e turma 2 (3 $3^{\text {a }}$ fase), semestre 2015-1, do Curso Superior de TGC, na modalidade EaD, da UNESC, Criciúma/SC. Participaram da amostra $62,9 \%$ dos acadêmicos. A avaliação ocorreu em onze disciplinas, cinco da $4^{\underline{a}}$ fase e seis da $3^{\underline{a}}$ fase.

Como instrumento de pesquisa, foi utilizado o diário de bordo; relatórios por disciplina, gerados pela avaliação institucional aplicada aos discentes e consulta ao Projeto Pedagógico do Curso (PPC). O instrumento de avaliação institucional estruturase em três blocos: Autoavaliação discente, Avaliação do material e recursos didáticos e Avaliação do desempenho docente. Os critérios para cada indicador do bloco constituem-se de 6 categorias: de MS (Muito satisfeito) a NA (Não sei avaliar). Destes, é extraída a média ponderada, em uma escala de zero a dez. A avaliação ocorreu ao 
término de cada disciplina, por adesão. Apresentam-se também a média aritmética dos indicadores de cada bloco, no total de disciplinas avaliadas.

\section{EDUCAÇÃO A DISTÂNCIA: PRINCÍPIOS E INDICADORES DE QUALIDADE}

Os princípios educacionais devem ser norteadores das concepções pedagógicas dos projetos em EaD e "envolvem a compreensão dos marcos conceituais, refletindo sobre os componentes epistemológicos, as abordagens e estratégias para viabilizar projetos nessa modalidade", como afirmam Zanette et. al. (2012, p.16). Para Cortelazzo (2013, p.20), os princípios fundamentais da educação

presencial e a distância são: autonomia, ação comunicativa, colaboração, acessibilidade e equidade.

A autonomia é a habilidade de se responsabilizar pela própria aprendizagem de acordo com o nível de ensino, a partir de um plano de estudo com os recursos necessários. O desenvolvimento desse princípio necessita de uma metodologia que implique na autonomia, envolvendo o aluno no planejamento, acompanhamentos e avaliação da sua aprendizagem de forma reflexiva (CORTELAZZO, 2013, p.20).

A ação comunicativa no fazer docente e na atuação discente deve ser bi e multidirecional, que promovam inquietações e questionamentos. Para Neder (2000, p.118), a comunicação interativa entre todos os integrantes do processo, no sentido de comunicação-intervenção é fundamental na EaD. Se adequadamente promovida, desencadeia a prática do aluno proativo e pesquisador. O princípio da colaboração é a base de uma parceria sólida e produtiva e requer que os sujeitos "compartilhem saberes e experiências tanto para aprender como para praticar suas habilidades e competências com os outros, para reelaborar o conhecimento existente ou para produzir novos conhecimentos" (CORTELAZZO, 2013, p.22).

A acessibilidade como princípio educativo está associada à estruturação e sistematização do conhecimento, enquanto direito do aluno, desde a disponibilização de plataforma tecnológica que permite o acesso ao conhecimento; aos materiais didáticos, pedagogicamente acessíveis e dimensionados aos diferentes estilos de aprendizagem; à qualidade no atendimento, no acesso e acervo de livros e outros 
materiais de aprendizagem, entre outros. A equidade, como princípio, refere-se às possibilidades igualitárias no contexto educativo. Cortelazzo (2013, p.24) cita a equidade como a base nas dimensões educacionais, socioeconômica, de gênero e raça. A EaD implica em educação democrática de qualidade que seja eficaz e invista superação das condições de desigualdade.

No cenário brasileiro, a EaD normatizada por legislação nacional tem instituído sua definição e referenciais de qualidade. Bittencourt (2014, p.68) cita que, mesmo sem ter a imposição de um modelo único de $\mathrm{EaD}$, há um rigor no controle das IES, com o intuito de coibir a precarização da educação, garantindo condições para a oferta de serviços educacionais de qualidade. Os programas podem apresentar diferentes desenhos, múltiplas combinações de linguagens, recursos educacionais e tecnológicos. Nesse sentido, o MEC, no documento norteador (BRASIL/MEC, 2007) reconhece que a modalidade de $\mathrm{EaD}$ tem características, linguagem e formato próprios, exigindo administração, desenho, lógica, acompanhamento, avaliação, recursos técnicos, tecnológicos, de infraestrutura e pedagógicos condizentes.

$\mathrm{Na}$ gestão pedagógica, estão inclusas todas as ações e procedimentos que serão executados em um curso a distância - planejamento, coordenação, execução, acompanhamento e avaliação do processo ensino e aprendizagem. Inclui as aulas a distância, o sistema tutorial e a produção do material didático. Além disso, é necessário definir a logística de distribuição física ou virtual em tempo hábil para a utilização dos alunos nas atividades de aprendizagem. Uma questão indiscutível, como cita Bittencourt (2013, p.77), "é a necessidade de assumir uma abordagem sistêmica para sustentar a gestão pedagógica na EaD". Implica em responsabilidade e comprometimento em sustentar e dinamizar o processo administrativo e pedagógico do curso, zelando pelo funcionamento eficiente e eficaz de todas as etapas, recursos humanos e tecnológicos envolvidos.

Conceitualmente, a avaliação deve possibilitar o diagnóstico de uma situação problema e oportunizar condições para modificá-la ou não, conforme as necessidades detectadas. Para Cortelazzo (2013, p.160), a relevância do processo de avaliação situase no objetivo de redirecionar as ações, orientações e replanejamento das atividades. Constitui-se como um dos fundamentos da $\mathrm{EaD}$ e contempla aspectos relevantes para 
a melhoria dos projetos. A análise deve contemplar a avaliação da aprendizagem, da gestão administrativa e pedagógica do curso e da modalidade de ensino. $O$ ato de avaliar, segundo Luckesi (2010), constitui-se em atribuir um valor ou uma qualidade, a partir de indicadores ou critérios assumidos como válido e, portanto, não são absolutos, mas comprometidos com as circunstâncias onde ocorrem. Serve para estatísticas e decisões políticas institucionais e, principalmente, é uma forma de discentes, docentes e IES, situarem-se sobre os resultados do processo de ensino e aprendizagem.

\section{O PROCESSO DIDÁTICO-PEDAGÓGICO DO CURSO DE TECNOLOGIA EM GESTÃO COMERCIAL NA MODALIDADE EAD: ANÁLISES PRELIMINARES}

O Curso de TGC da UNESC ocorre na presencialidade e a distância. Em 2013, iniciou a $1^{\underline{a}}$ turma na modalidade de EaD. A IES é credenciada para oferecer cursos superiores na modalidade a distância pela Portaria $n^{\circ}$ 45, de 22 de janeiro de 2013, do MEC, em seu polo sede. O curso surgiu em parceria com o Conselho Regional de Representantes Comerciais do Estado de Santa Catarina - CORE, com o objetivo de formar profissionais para atuar em diversos segmentos da área comercial, apresentando as atuais ferramentas de gestão, comunicação, vendas, empreendedorismo, dentre outras.

Conforme consta no PPC (UNESC, 2014), a arquitetura pedagógica organiza-se em estrutura curricular modular. Os módulos são semestrais e o acadêmico tem direito à Certificação de Qualidade Profissional, de acordo com a Resolução № 03/2002/CNE-CP, que institui as Diretrizes Curriculares Nacionais Gerais para os cursos superiores de tecnologia, conforme os módulos são concluídos. Em cada módulo, as disciplinas ocorrem em seis semanas, com duas disciplinas concomitantes.

O modelo pedagógico do curso apoia-se no conceito de planejamento estruturado. As ações didático-pedagógicas das aulas são previamente planejadas por meio de roteiros de aprendizagem, semanais, com uma similaridade de formatação com o intuito de facilitar ao estudante, o acesso à informação de forma semelhante em todas as disciplinas. Os roteiros são publicados no Ambiente Virtual de Aprendizagem (AVA), com as orientações para atividades de estudo como: leitura, vídeos, pesquisas, 
atividades em diversos formatos, de acordo com a natureza e especificidade de cada disciplina (UNESC, 2014). Os materiais didáticos são desenvolvidos por professoresautores de forma colaborativa com a equipe de produção do Setor de Educação a Distância (SEAD) e disponibilizados aos acadêmicos.

As aulas presencias on-line são semanais e transmitidas por meio de conferência via web a partir do polo sede. A aula pode ser gravada por meio de dois sistemas: filmagem padrão com filmadora digital; e filmagem por webcam com o uso dos recursos de gravação da ferramenta de webconferência utilizada para a transmissão das aulas. A equipe de produção de vídeos do SEAD e um monitor assessoram o professor. Os estudantes podem participar das aulas semanais, presencialmente, no polo sede em Criciúma (SC); acompanhar em tempo real via Internet e interagir com colegas e professor por meio do chat disponível na ferramenta de conferência via web; e/ou assistir à aula, durante a semana, no horário e tempo adequados às suas necessidades, acessando os vídeos publicados no AVA. Nas aulas presencias on-line, o professor planeja este tempo entre apresentação e debate sobre 0 conteúdo.

A atuação no sistema de tutoria e monitoria ocorre por meio dos recursos do AVA (fórum, chat, e-mail), webconferência e telefone. Apesar de disponíveis, os sistemas de correio, telefone-fax são pouco utilizados pelos alunos. A tutoria também ocorre na presencialidade, com calendário definido no início da disciplina. A sala da monitoria e da tutoria está localizada no SEAD da Instituição. O processo de interação também define a aprendizagem: pela interação direta e a aprendizagem sistematizada. A interação é direta, relaciona-se com a interação do indivíduo com o conhecimento quando textos impressos ou digitais, quando ouvem preleções, assistem às videoaulas e/ou vivenciam novas situações, como cita Cortelazzo (2013, p.168).

No curso, o acompanhamento das aulas e desenvolvimento das atividades pelos estudantes, ocorre de forma sistemática, integrando as ações da monitora que acompanha o mesmo, diariamente, via AVA, e dos tutores. A avaliação da aprendizagem ocorre em atividades a distância e presenciais. As avaliações a distância são semanais, com o uso dos recursos tecnológicos do AVA e atendem aos objetivos 
das disciplinas. As mais usuais são: quiz on-line (questões objetivas e subjetivas); trabalhos (publicados no AVA); fóruns de debate e resolução de situações-problema.

A avaliação da aprendizagem é um processo no qual se procura "identificar, aferir, investigar e analisar as modificações do comportamento e rendimento do aluno, do educador, do sistema", verificando se houve elaboração do conhecimento teórico ou prático (SANT'ANNA, 1995, p.31). Para Vallin (2014, p.38), avaliar bem indica a avaliação do processo de aprendizagem em sua totalidade e no processo, semana a semana, atividade a atividade e realimentar as orientações e decisões sobre o andamento e desenvolvimento dos estudos de forma dinâmica, considerando-se as avaliações parciais ou processuais. Conforme Resolução n.05/2013 CSA da Unesc, para aprovação do acadêmico nas disciplinas na $\mathrm{EaD}$, a média ponderada das notas deve ser igual ou superior a seis $(6,0)$, com avaliações a distância, que equivalem a $40 \%$ da média e avaliação presencial, que equivale a $60 \%$ da média final.

Na perspectiva de gestão de cursos e gestão de $\mathrm{EaD}$, o sistema de avaliação deve contemplar os processos de avaliação institucional, compreendida no contexto de um processo pedagógico. Nos cursos a distância da Unesc, esta é contínua com o objetivo de aprimorar a qualidade do ensino, pesquisa, extensão e gestão administrativa. Os instrumentos de avaliação são planejados e aplicados de forma a atender aos indicadores de qualidade na EaD, pelo Ministério da Educação (MEC). Bittencourt (2013, p.70) afirma que estes orientam os projetos e envolvem dimensões que contemplam "os aspectos pedagógicos, os recursos humanos e infraestrutura para atender à complexidade e à necessidade de uma abordagem sistêmica".

\section{AVALIAÇÃO DO PROCESSO PEDAGÓGICO NA PERCEPÇÃO DOS ACADÊMICOS: ANÁLISE DOS DADOS}

Os acadêmicos integrantes das duas primeiras turmas do curso, em sua maioria, residem nos municípios próximos do polo sede, em Criciúma/SC (73,79\%). Já atuam no mercado de trabalho (100\%), com idade entre 20 e 40 anos $(87,38 \%)$ em sua maioria e mais de $50 \%$ do grupo é do sexo masculino. 
A avaliação do processo didático-pedagógico, na ótica do discente é relevante para a melhoria dos processos de gestão administrativa e pedagógica, por possibilitar o diagnóstico de uma situação-problema e oportunizar condições para modificá-la ou não, conforme as necessidades detectadas. $O$ instrumento de avaliação institucional aplicado aos discentes, ao final das disciplinas, é composto por três blocos: Autoavaliação discente, Avaliação do material e recursos didáticos e Avaliação do desempenho docente. Os critérios para cada indicador do bloco são categorizados entre MS (Muito satisfeito) a NA (Não sei avaliar), em um total de 06 categorias. Destes, é extraída a média ponderada, em uma escala de zero a dez. Os estudantes são convidados a participarem voluntariamente da pesquisa e esta participação tem se mantido em níveis superiores a 50\%. Apresentam-se, também, a média aritmética dos indicadores de cada bloco, no total de disciplinas avaliadas.

$\mathrm{Na}$ análise dos relatórios de avaliação do SEAI, aplicados aos discentes da $3^{\text {a }}$ fase e $4^{\text {a }}$ fase do curso, em 2015-1, obtiveram-se os seguintes resultados, tendo em vista a participação média, por disciplina, de 31 acadêmicos: no bloco Autoavaliação discente, os indicadores e as médias de avaliação foram: cumprimento de atividades a distância $(9,07)$; participação ativa nas atividades propostas pelo professor em fóruns, chats, webconferências e/ou reuniões virtuais os resultados $(8,94)$; utilização de outras fontes de consulta além das indicadas pelo professor $(8,8)$; contribuição para um ambiente favorável à aprendizagem $(9,09)$. Observou-se que 0 indicador de cumprimento das atividades foi o melhor avaliado. Como sugestão dos acadêmicos, ampliar os prazos contribuiria na eficiência do processo: "No meu ver, o tempo para postagem das atividades é muito curto, pois, como faço à distancia por não poder estar presencialmente, não tenho tempo para ver as atividades todos os dias..."; "Apenas rever os tempos de postagem, pois realmente ficam apertados, sugiro que fiquem abertos por mais tempo e não por apenas uma semana, assim na semana que eu estou muito atarefado fica acumulado para um outra semana que eu consiga estudar mais, acho essa flexibilidade muito importante". Como fator de menor incidência, tem-se o uso outras fontes de consulta. Sobre isso, um acadêmico citou que: "Não temos tempo hábil para em seis semanas, ou no decorrer de uma semana, lermos livros e outro materiais complementares para as matérias". Entretanto, é indicativo de melhorias nos 
processos e propõem-se ao professor/tutor que incentive o estudante na busca de outras fontes de estudos e pesquisas.

No bloco de Avaliação do material e os recursos didáticos, todos os indicadores foram bem avaliados, com destaque para o atendimento da monitoria (disponibilidade, resolução de problemas, acompanhamento), com média 8,87. Os demais indicadores, obtiveram as seguintes médias de avaliação: qualidade do material didático impresso $(8,83)$ e digital $(8,06)$; linguagem clara e objetiva do conteúdo didático $(8,66)$; articulação entre teoria e prática $(8,57)$; qualidade da webconferência $(8,34)$. Os dados revelam que os recursos e materiais didáticos, físicos e virtuais no AVA obtiveram boa aprovação. Entretanto, podem ser melhorados. Como cita um dos acadêmicos, "o material impresso não tinha todo o conteúdo das aulas. As aulas eram carregadas de muita leitura, poderia ser apresentado em tópicos e depois explicado o conteúdo de forma mais clara, pois a leitura já está disponível no material didático".

Os materiais e recursos interferem diretamente na ação comunicativa docente e discente que necessita de metodologias e tecnologias adequadas à EaD. Como cita Neder (2000), deve ser bi e multidirecional, além de promover inquietações e questionamentos. As atividades virtuais mediadas por tecnologias interativas estão conseguindo aumentar a sensação de proximidade percebida pelos alunos. Como afirma Tori (2010, p.27), uma videoconferência pode aproximar alunos e professores e um chat pode aproximar alunos entre si. Entretanto, a proatividade dos integrantes do processo educativo é fundamental para que essa interação aconteça.

O último bloco busca avaliar o desempenho do docente, de forma a gerar indicadores para os processos de melhoria da qualidade de ensino. Os indicadores e suas médias são: cumprimento de cronograma $(9,06)$; uso de linguagem clara e objetiva $(8,83)$; organização da sala virtual $(8,77)$; articulação entre teoria e prática $(8,58)$; esclarecimento de dúvidas (8,93). A avaliação do desempenho docente apresenta a média geral 8,86 , com destaque para o cumprimento do cronograma estabelecido pela disciplina. Este pode ser o indicador de que a roteirização das aulas é fator determinante para o bom planejamento e execução do processo de ensino e aprendizagem na EaD. Na citação dos acadêmicos, evidenciam-se a satisfação com o 
processo educativo ao afirmar que, "... a professora é excelente"; "o curso está muito bom"; "as matérias tiveram uma contribuição significativa para o meu dia a dia".

Segundo Zanette et. al. (2012, p.18), as relações entre educador e educando modificam-se na EaD; a aprendizagem potencializada pela interação entre os sujeitos modifica o papel do professor para organizador das situações de aprendizagem. "Assim, deve disponibilizar múltiplas situações que permitem a intervenção e a participação do estudante numa multiplicidade de conexões". Compete a ele criar

ambientes de aprendizagem que oportunizem o desenvolvimento da criatividade, do senso crítico, da investigação, da resolução de problemas, entre outros.

Como cita Cortelazzo (2013, p.160), a aprendizagem é "resultante de ações intencionais para que sejam alcançados determinados projetivos, podendo ser individual, solitária, social, cooperativa e colaborativa". Deve ocorrer de forma sistematizada e mediada por pessoas, apoiada na EaD por meios de comunicação que são organizados de forma que os estudantes sigam rotas e aprendam. A complexidade e a necessidade de uma abordagem sistêmica nas disciplinas e cursos em EaD implicam em referenciais de qualidade, na forma de um sistema integrado que envolve, fundamentalmente, aspectos pedagógicos, recursos humanos e infraestrutura.

\section{CONCLUSÕES PRELIMINARES}

A avaliação e reavaliação de ações nos processos pedagógicos dos cursos superiores na modalidade de $\mathrm{EaD}$ são relevantes para o sucesso desses projetos. Possibilitam diagnosticar uma situação e, a partir das necessidades detectadas, oportunizar condições para modificá-las por meio de novas ações. A complexidade da modalidade exige a reflexão permanente sobre fatores diversos que interferem diretamente no processo educativo.

A participação do acadêmico no processo de avaliação institucional é fundamental por contribuir na melhoria dos processos na gestão pedagógica dos projetos de EaD. Fatores como o aumento da adesão nas matrículas dos acadêmicos de cursos presenciais em disciplinas a distância e a redução da evasão no curso - a média de evasão na turma 2 é 7,7\% menor em relação à turma 1 - podem ser 
indicadores de novas avaliações e reflexões sobre a proposta pedagógica, contribuindo para a melhor aceitação da EaD na IES.

A análise da percepção dos acadêmicos sobre o processo pedagógico nos três blocos avaliados apresentou média de aprovação superior a oito em todos os indicadores. A participação do acadêmico no processo pedagógico é evidenciada na autoavaliação pelas médias obtidas no cumprimento das atividades a distância, na participação ativa das proposições dos professores e na contribuição para um ambiente favorável à aprendizagem com media geral de 8,93. Os materiais e recursos didáticos foram bem avaliados com média geral 8,60, com destaque a qualidade do material didático impresso e o bom atendimento da monitoria. O mesmo ocorreu na avaliação do desempenho do docente, cujo bloco apresentou média geral de 8,86 com destaque para a organização e planejamento das atividades e bom atendimento da tutoria. Os dados obtidos na avaliação são indicadores para os processos de melhoria e estabelecimento da qualidade de ensino. Esses indicadores são enviados aos docentes e, semestralmente, avaliados em conjunto pelo Núcleo Docente Estruturante - NDE e a Coordenação de Curso, no sentido de pensar e repensar as práticas metodológicas.

Assim, pode-se afirmar que a avaliação institucional no curso é fundamental para a manutenção, renovação e melhorias nos processos educacionais. Constitui-se em um processo contínuo de aprimoramento da qualidade do ensino e gestão administrativa. Responde às ações dos professores e gestores envolvidos, legitimando o empenho e a busca da qualidade do curso. Dessa forma, contribui na validação do projeto e possibilita à IES investir em novas turmas nesta modalidade.

Portanto, o processo didático-pedagógico do primeiro curso superior na modalidade de Educação a Distância, apresenta elementos indicativos de avaliação positiva pelos discentes do curso. Assim, pode-se afirmar que a avaliação institucional no curso é fundamental para a manutenção, renovação e melhorias nos processos educacionais. Constitui-se em um processo contínuo de aprimoramento da qualidade do ensino e gestão administrativa.

\section{REFERÊNCIAS}


BITTENCOURT, D. F. A metodologia de autoavaliação institucional na educação a distância. Palhoça: Unisul, 2013.

BRASIL/MEC. Referências de Qualidade na Educação a Distância (2007). Ministério da Educação. Disponível em:

$<$ http://portal.mec.gov.br/seed/arquivos/pdf/legislacao/refead1.pdf >Acesso em: Dez 2014.

CORTELAZZO, I.B.C. Prática Pedagógica, aprendizagem e avaliação em educação a distância. Curitiba: InterSaberes, 2013.

LUCKESI, C. C. Prefácio. In: TENÓRIO, R.M.; LOPES, U.M. (org). Avaliação e Gestão: Teorias e Práticas. Salvador, BA: EDUFBA, 2010. p. 9-13.

LEVY, Pierre. Cibercultura. São Paulo: Atlas, 1999.

NEDER, Maria Lúcia Cavalli. A orientação Acadêmica na Educação a Distância: a perspectiva de (re)significação do processo educacional. In: PRETI, Orestes (org). Educação a Distância: Construindo significados. Cuiabá: NEAD/IE - UFMT; Brasília: Plano, 2000.

OLIVEIRA, S. L. Trabalho de Metodologia Científica. São Paulo: Pioneira, 1999.

PPC/UNESC, Universidade do Extremo Sul Catarinense. Projeto Pedagógico do Curso de Tecnologia em Gestão Comercial a Distância. Criciúma: UNESC, 2014.

SAMPIERI, R.H.; et.al. Metodologia de Pesquisa. 3. ed. SP: Macgraw-hill, 2006.

SANTOS, C.R. dos; GIACOMAZZO, G.F.; FIUZA, P.J.; ZANETTE, E.N. Educação a Distância, Inovação e Práticas Pedagógicas: Trajetórias na Formação Docente no Ensino Superior. In: ZANETTE, E.N.; GIACOMAZZO, G.F.; FIUZA, P.J. (Orgs).

Tecnologias e Inovações nas Práticas Pedagógicas: Trajetórias e Experiências. Jundiaí/SP: Paco Editorial. 2012. p.25-35.

SANTA'ANNA, I. M. Por que Avaliar? Como Avaliar? Critérios e instrumentos. Petrópolis: Vozes, 1995. 
TORI, R. Educação sem Distância: As tecnologias interativas na redução da distância entre ensino e aprendizagem. São Paulo: SENAC, 2010.

VALLIN, C. Educação a Distância e Paulo Freire. In: Revista Brasileira de Aprendizagem Aberta e a Distância. Out. 14. SP: ABED, 2014. p. 23-42.

ZANETTE, E.N.; SANTOS, C.R. dos; GIACOMAZZO, G.F.; FIUZA, P.J. Educação a Distância no Ensino Superior: A experiência de uma equipe multidisciplinar. In: ZANETTE, E.N.; GIACOMAZZO, G.F.; FIUZA, P.J. (Orgs). Tecnologias e Inovações nas Práticas Pedagógicas: Trajetórias e Experiências. Jundiaí/SP: Paco Editorial, 2012. p.13-24. 